\title{
“Withered Tree" Concept Host, Achieved by Global Contraception and Abortion, Secondary to Fragmented Germ Cells, Agonizingly Reduced Endogenous Estrogen/Androgen, Defaulted Genomic Repertoire, Deranged Cell Metabolism, Metabolic Syndrome, Result in Failure of Pharmacological Therapeutics with Advanced Technologies
}

\author{
Elizabeth Jeya Vardhini Samuel1, Nagarajan Natarajan'2, Sri Kumar ${ }^{3}$ \\ ${ }^{1}$ Department of General Medicine, MM Hospital, Tanjore, India \\ ${ }^{2}$ Department of General Medicine, Pondicherry Institute of Medical Sciences, Pondicherry, India \\ ${ }^{3}$ Dhonavur Fellowship Hospital, Dhonavur, India \\ Email: elizabethjsamuel@gmail.com
}

Received 27 March 2015; accepted 24 April 2015; published 30 April 2015

Copyright (C) 2015 by authors and Scientific Research Publishing Inc.

This work is licensed under the Creative Commons Attribution International License (CC BY).

http://creativecommons.org/licenses/by/4.0/

(c) (i) Open Access

\begin{abstract}
Background: In spite of advanced technologies and drug discoveries, morbidity and mortality were undoubtedly increasing in the era of contraception and abortion. Aims: Altruistic correlation of increasing morbidity, mortality, with contraception, abortion was planned for. Methods: In 2012, a retrospective analysis of prevalence of mortality in 350 patients of 20 - 35 years, 35 - 50 years and $>50$ years from data collected between 2003 and 2012 by convenient, stratified random sampling, from community, hospital, and its association with contraception and abortion status was undertaken; simultaneously, serum estrogen levels obtained from 105 patients were analyzed. In 2014, randomly chosen 8 males, of the 3 age groups, from a different community, whose life partners had undergone sterilization, were assessed for their serum testosterone levels. Results: Contraception users exhibited 3 - 4 fold increased mortality [p < 0.0005] amongst 20 - 50 years and 6 How to cite this paper: Samuel, E.J.V., et al. (2015) "Withered Tree" Concept Host, Achieved by Global Contraception and Abortion, Secondary to Fragmented Germ Cells, Agonizingly Reduced Endogenous Estrogen/Androgen, Defaulted Genomic Repertoire, Deranged Cell Metabolism, Metabolic Syndrome, Result in Failure of Pharmacological Therapeutics with Advanced Technologies. Open Journal of Preventive Medicine, 5, 186-195. http://dx.doi.org/10.4236/ojpm.2015.54022
\end{abstract}


fold increased mortality among $>50$ years $[p<0.0005]$. Endogenous estrogen was reduced in $75 \%$ $[p<0.0005]$ of contraceptive users. Plasma testosterone was reduced in males observing contraception, to less than $50 \%$ of normal, e.g. $1.3 \mathrm{ng} / \mathrm{ml} ; 66.6 \%$ contraception users aged 20 - 35 years had reduced [p $<0.0005]$ testosterone; 100\% of male contraception users aged $36-70$ years showed reduced testosterone [p $<\mathbf{0 . 0 0 0 5}$ ]. Conclusion: The "withered tree akin host" concept is contraception, abortion, with smashed fragmentation of germ cells. Reduced endogenous estrogen, androgen [dried up, destroyed life factors] result in deranged cell metabolism, cell cycle, and defaulted genomic repertoire, leading to failure of all established pharmacological therapeutics, including advanced technologies which yield gratifying results in non contracepted people today and in every one, before the era of contraception; subsets of people, host with contraception, with destroyed life factors, behave helplessly, concerning therapeutic applications, compared with subsets of people, host without contraception, with intact genomic repertoire, God ordained Life factors, make a remarkable recovery. Contraception reversal replants the germ cells [germ cells destruction stops], hormones rejuvenate to $\mathbf{7 9 . 9 \%}$ of age normal, and diseases abate with recovery.

\section{Keywords}

Withered Tree Concept Host, Deranged Cell Metabolism, Defaulted Genomic Repertoire, Deranged Mitochondrial Pathways, Contraception Reversal, Metabolic Syndrome Reverts

\section{Introduction}

After the implementation of contraception, abortion, specially permanent sterilization-tubectomy, and vasectomy in our country, with a presumption of no associated side effects, i.e. there was no study done prior to assessing the presumed safety or therapeutic indication of sterilization procedures, contracepted couple experienced illnesses like obesity, diabetes mellitus, and acute coronary syndrome, including early demise at the young age; as the implementation of global contraception/abortion stealthily increased, global incidence, prevalence of diseases, and mortality had increased glaringly and undoubtedly and could not be explained as to its cause, otherwise.

Molecules which were performing remarkably, as per pharmacological therapeutics, before the era of contraception, were failing to achieve their therapeutic goals with a set back; in order to explain the failure of therapeutics [after the era of contraception-presumed to have no side effects-vacuum in information towards cause and effect phenomenon], help was sought by calculating odds ratios, hazard ratio, confidence interval, and number to treat and to give power to medicines, which had already been established with detailed pharmacological profile, but was of no avail.

Metabolic defect of reduced formation of high density lipo protein from low density lipo protein was observed, suggesting defaulted cell membrane synthesis and steroid hormone synthesis; metabolic syndrome was recognized globally, with achievement of global contraception; acquired mitochondrial pathologies were identified; basically, cell metabolism, which was under the surveillance of endogenous estrogen and androgen, got deranged consequent to wantonly acquired germ cells destruction, and secondary to contraception abortion, to result in possible mutations, degenerative diseases, and neoplasms. Concept of host resembling "withered tree" stems as etiology, to explain globally increased prevalence of morbidity, mortality.

Hence, an altruistic analysis for association of morbidity and mortality, with status of contraception and abortion in the host, was planned.

\section{Methods}

Data collected was divided into 3 age groups, namely, 20 - 35 years, 36 - 50 years, and >50 years; though people from the community are visiting the hospital, analysis of hospital patients alone can create a bias, hence data from the community, hospital, health screening camps, of different geographical locations were included; data from each person depicted, prevalent diseases, status of contraception, hysterectomy, type of oil ingested, life style, level of nutrition, presence of anemia; the data was tabulated as prevalent morbidity, mortality, matched 
against the variables in each age group; retrospective bio-informatics analysis was done, by plotting histograms for the 3 age groups and cumulative graphs for each disease and mortality in 2012; an example of tabulation of the data is provided in the supplementary file.

In 2003 house to house survey [1] in the community, spread over 3 weeks, was conducted by the corresponding Author, to collect data of prevalent diseases of 100 people; the people who were present during the survey were included at random, by convenient sampling into the 3 age groups, namely, $20-35$ years, $35-50$ years, and $>50$ years, to include a minimum of 30 people in each age group; serum estrogen estimation was done for 12 people as per their request; the reduced estrogen levels [5-8 pg] found in young contraceptive users, was the eye opener, leading to further data analysis.

In 2004 data of 93 hospital patients was collected over a period of 6 months, including prevalent diseases, mortality, Status of contraception, life style, nutrition, type of oil ingested, level of hemoglobin and were assigned to the 3 age groups, by stratified random sampling with a minimum of 30 patients in each age group; serum estrogen estimation was done for all 93 patients; the data was tabulated matching diseases, mortality against status of contraception and other variables; one patient was a foreign national.

In 2011, 96 people [43 couples] working in different states of our nation had attended a health screening camp conducted in the community, spread over 3 days and their data was analyzed after assigning into the 3 age groups at random, for association of diseases , mortality with status of contraception, hysterectomy and other variables; effect of contraception in both partners also could be analyzed; none had sedentary life style, low nutrition or anemia or had worn tight attires around the pelvis.

In 2012, data of 61 hospital patients including a foreign resident, from another geographical location, was collected over a span of 6 months, assigned to the 3 age groups at random and was pooled to the other data from 2003, 2004, 2011 and retrospective bio informatics analysis was undertaken for the 350 patients in 2012, by Histogram, for the 3 age groups and cumulative graphs for each disease and mortality.

Every participant was informed about their data being included for study purpose and the concerned hospital Authorities were also informed; an engineering college student did the bio informatics analysis as his project.

In 2014, randomly chosen 8 males, [2] of the 3 age groups, from a different community, whose life partners had undergone sterilization, were assessed for their serum testosterone levels.

\section{Results}

Variables like nutrition, lifestyle, presence of anemia, tight attires around pelvis were nullified, since none of them were malnourished, or anemic, or wore tight attires around the pelvis. Contraception users Figure 1 exhibited 3 - 4 fold increased mortality $[\mathrm{p}<0.0005]$ among 20 - 50 years and 6 fold increased mortality among $>50$ years $[\mathrm{p}<0.0005]$. Contraception users depicted $275 \%$ increase in diseases Figure 2 among 20 - 35 years, 35 50 years age group [p $<0.0005] ;>50$ years people without contraception also develop degenerative diseases, since the endogenous estrogen, androgen decrease after 37 years of age, naturally to $15 \mathrm{pg},<2.6 \mathrm{ng}$ respectively. Absence of diseases was seen by the analysis of heath screening camps, 80\% - 90\% [p $<0.0005]$ Figure 3 in the people without contraception only in 20 - 35 years age, 35 - 50 years age group. Contraception correlates absolutely with increased morbidity, mortality, in young age $<50$ years; absence of contraception correlates absolutely with absence of diseases, in young age $<50$ years. Endogenous estrogen [3] was reduced in $75 \%$ [p $<$ 0.0005] of contraceptive users.

Plasma testosterone was reduced in males observing contraception, to less than $50 \%$ of age normal, e.g. 1.3 $\mathrm{ng} / \mathrm{ml} ; 66.6 \%$ contraception users aged $20-35$ years had reduced $[\mathrm{p}<0.0005]$ testosterone; $100 \%$ male contraception users, aged $36-70$ years showed reduced testosterone $[\mathrm{p}<0.0005]$.

\section{Discussion}

Population aging is transforming the world in dramatic and fundamental ways, age distribution of populations have changed and will continue to change radically, due to long term declines in [4] fertility rates; its predicted in another 30 years, younger age group of $<5$ years will become $5 \%$ [alas unchecked, disappearing human race].

Global contraception, abortion with resultant smashed destruction of [5] germ cells, associated reduction in endogenous estrogen, androgen, on whose surveillance the cell cycle, cell metabolism is dependent upon, leads to deranged cell metabolism, metabolic syndrome, [6] [7] defaulted genomic repertoire, with consequent in- 


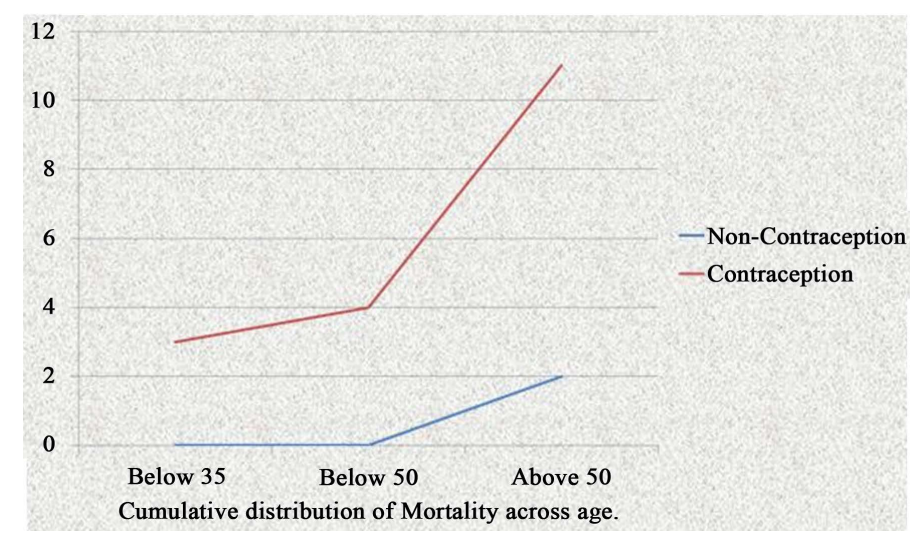

Figure 1. Prevalence of mortality, contraception.

\section{Disease Prevalence and age group.}

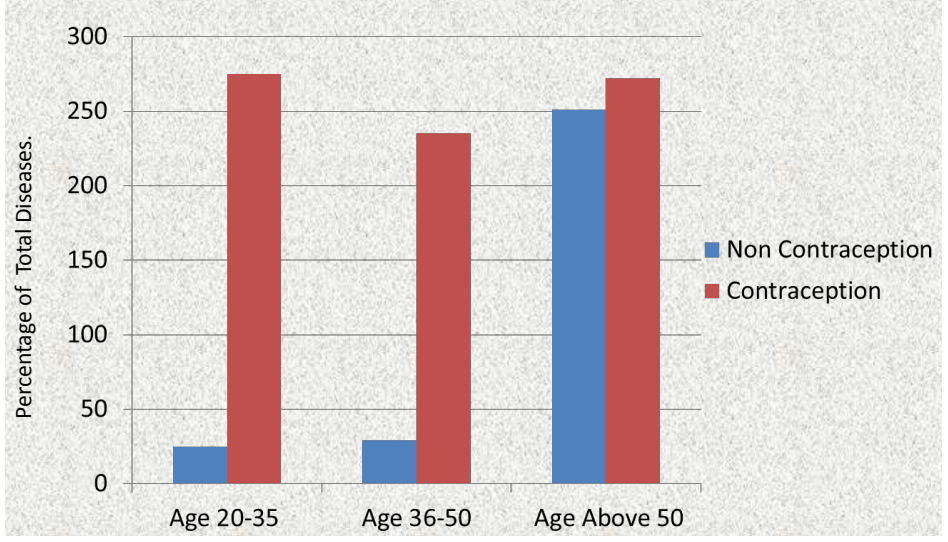

Figure 2. Prevalence of diseases, contraception.

\section{Absence of disease- nil contraception}

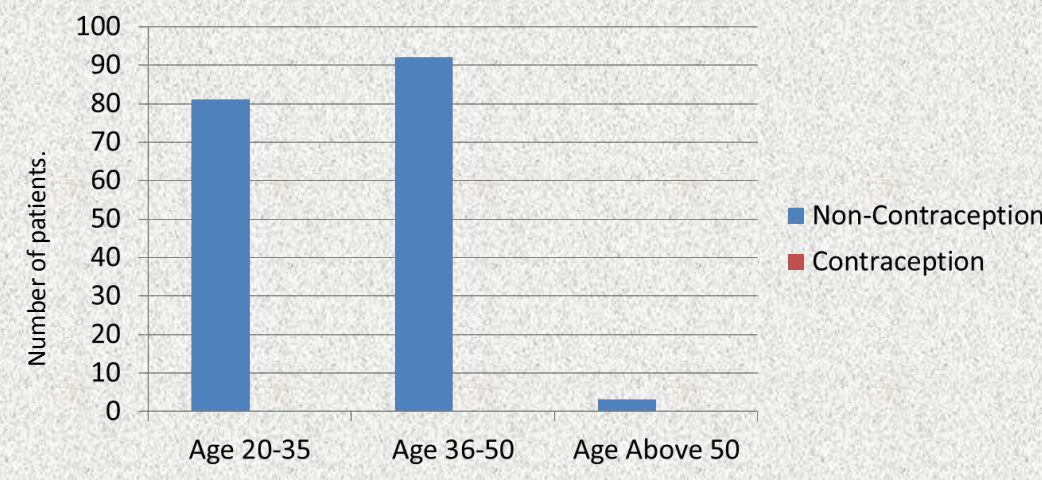

What a Bliss to have no disease with nil contraception!!

With contraception no disease is not seen i.e., no escape as per human physiology

from degenerative diseases - painful tragedy-prevalent-true, but not recognized by doctors/govt./people

Figure 3. Prevalence of absence of disease, non-contraception. 
crease in degenerative diseases - "withered tree concept host"- e.g. T2 diabetes mellitus, hypertension, rising by 15 - 50 fold [8] amongst 20 - 50 years of people using contraception.

The fragmented germ cells, i.e. ring chromosomes, acentric fragments, chromatid breaks are identified as foreign and autoimmune antibodies are detected to the above fragmented chromatids resulting in entire spectrum of auto [9] immune diseases increasing by $15-40$ fold amongst 20 - 50 years of contraception users.

The concept is when the endogenous estrogen, androgen decrease with contraception, abortion, [withered tree concept Host] cell cycle of differentiation followed by controlled multiplication, defaults leading to increase in [10] neoplasms, cancers, mutations of, e.g. glucokinase, hepatocyte nuclear transcription factors leading to MODY, including mitochondrial pathologies; 10 - 20 fold increase in breast cancer, 20 - 30 fold increase in prostate cancer, 20 - 40 fold increase in cancer cervix is seen amongst contraception users of 20 - 50 years of age.

Secondary to aborted blood pollution, contraceptive menstrual blood pollution, evidenced by rising environmental estrogen, $\alpha$ feto protein, $\beta$ human chorionic gonadotropins, infectious [11] [12] diseases' prevalence have increased for e.g. tuberculosis which had earlier been documented as curable in the era before contraception, has increased by 15 - 30 fold amongst contraception users, progressing to destroyed lungs; the concept is, the host with contraception, abortion is akin to "withered tree" damaged \{eaten up easily by soaring virulent infections promoted by environmental aborted blood pollution [Alas! Young parents with contraception, abortion, die like flies by infectious diseases including severe sepsis, less virulent fungal infections, tuberculosis, rickettsial infections, in spite of newer antimicrobials, protocols, policies, because their physique is akin to "withered tree", achieved unaware, by wantonly acquired, globally permitted, without evidence based practice-contraception, abortion].

Mitochondrial pathologies are transmitted [13] by matrilineal fashion, non-coding region of mitochondrial chromosome, referred to as D loop, is highly polymorphic, alterations in the mitochondrial DNA affect enzymes required for oxidative phosphorylation, leading to reduction of ATP supply, generation of free radicals, induction of apoptosis; contraception can culminate in mitochondrial pathologies by deranged cell metabolism, defaulted genomic repertoire, mutations achieved by reduced endogenous androgen, estrogen surveillance as a result of smashed fragmentation of germ cells.

The concept is [as portrayed above] with contraception, abortion the germ cells destruction and their associated hormonal reduction, leads to withered tree akin host, resulting in 3 - 6 fold increase in mortality amongst contraception users of 20 - >50 years in spite of advanced technologies, drug discoveries, therapeutic protocols, and policies.

Our therapies capitalize on the cells healing capacity, which defaults in the "withered tree" concept host, by acquired contraception, abortion, secondary to destruction of germ cells and associated decrease in endogenous estrogen, androgen, on whose surveillance the cell cycle, cell differentiation, controlled multiplication, genomic repertoire, cell metabolism is dependent upon.

Contraception reversal, specially including tubal [14] recanalisation, for permanent sterilization, replants the germ cells, i.e. stops destruction of the germ cells, associated with $79.9 \%$ restored synthesis of endogenous estrogen, androgen, correcting the defaulted genomic repertoire, deranged cell metabolism, thereby reversing metabolic syndrome [figures-supplementary files [14]. Since after hysterectomy the endogenous estrogen decreases to $0.4 \mathrm{pg} / \mathrm{ml}$, there's associated $500 \%$ increase in morbidity in this subset of people.

When a molecule is analyzed for, e.g. Olmesartan, [15] enalapril maleate, why they are not effective as they ought to be in nephropathy, cardiac failure, or some unusual side effects which is not detailed in the product monograph or pharmacology therapeutics text, by using odds ratio, number to treat, power to medicines, the studies cannot find the answer; molecule will perform as portrayed in the pharmacological text, in normal live human body, unaltered by acquired contraception, abortion, with intact germ cells, endogenous estrogen, androgen, robust cell cycle, metabolism, genomic repertoire; whereas in people with acquired contraception, abortion, the host is akin to "withered tree" with ongoing, perennial germ cells" destruction, [specially in permanent sterilization] reduced endogenous estrogen, androgen, defaulted genomic repertoire, metabolic syndrome secondary to deranged cell metabolism, cell cycle, cell differentiation, similar to, no possible effect of the therapeutic molecules in dead body, can they have any effect?; how can the molecule perform the same way, in physique with acquired contraception, abortion, with defaulted genomic repertoiret; we have to reconcile with facts of "withered tree" concept host in subset of people using contraception, with acquired $275 \%$ increase in neoplastic, degenerative, infectious, auto immune diseases, mortality and offer rectification as cause and effect phenomenon, to reverse permanent modes of contraception, halt, eradicate contraception, abortion from the face of the earth. 


\section{Conclusions}

Global contraception and abortion, results in smashed destruction of germ cells, consequent gross reduction in endogenous estrogen, and androgen, leading to deranged cell metabolism, defaulted cell cycle of differentiation, controlled multiplication, metabolic syndrome, and mutations including mt DNA similar to "withered tree", i.e. human live body, deprived of life factors by unaware, wantonly acquired contraception, and abortion, form the basis of failure of therapies, technologies, and molecules which otherwise will have been a success in subsets of people without contraception and abortion, but are blessed with uncurbed child birth, unlike people practising small family norms and one child policy.

This has resulted in 3 - 6 fold increase in mortality in contraception users, aged 20 - >50 years, consequent to rise in infectious diseases, neoplastic diseases, and degenerative and auto immune diseases, in spite of advanced technologies and therapeutics.

Another significant finding is that "withered tree" springs forth by $79.9 \%$, i.e. on contraception reversal including tubal recanalization, the germ cells destruction stops, replant of germ cells with regain in synthesis of endogenous estrogen, androgen by $79.9 \%$ of corresponding normal for age, results in decline in degenerative, neoplastic, autoimmune, infectious diseases; cell's healing capacity-genomic repertoire, cell metabolism is restored; metabolic syndrome regresses marvelously, e.g. new nail beds, hair follicles, angiogenesis, collaterals spring forth; embryo like healing capacity in the cells-genomic repertoire is restored $79.9 \%$ on reversing contraception and abortion.

Let the medical fraternity and the medical curriculum pave way for this awareness of, wantonly acquired early demise in young parents, by global contraception and abortion similar to "withered tree", and plan global protocols, policies and strategies, to revert and eradicate global contraception and abortion, destroying young lives in disguise.

\section{Key Points}

- Contraception, abortion achieves "withered tree" concept host, by destruction of germ cells leading to agonizingly reduced endogenous estrogen, androgen;

- Smashed destruction of germ cells, agonizingly reduced endogenous estrogen, androgen result in deranged cell metabolism, defaulted genomic repertoire, leading to 3 - 6 fold increase in mortality and unwanted early demise in young parents;

- Advanced technologies, therapeutics fail to reduce mortality in contraception users aged 20 - 50 years;

- 3 - 6 fold increase in mortality amongst contraception users aged 20 - >50 years, since the host component has become like withered tree [deprived of life factors];

- Contraception reversal restores cell function, metabolism by $79.9 \%$, since the germ cells destruction stops, endogenous estrogen, androgen's synthesis rises again by $79.9 \%$ of age normal, equal to flourishing back of "withered tree" concept host, materializing cause and effect phenomenon.

\section{References}

[1] Samuel, E.J.V., et al. (2014) Increasing Prevalence of Osteoporosis, Hypothyroidism and Endogenous Estrogen with Germ Cells. Open Journal of Rheumatology and Autoimmune Diseases, 4, 131-137. http://dx.doi.org/10.4236/ojra.2014.43019

[2] Elizabeth, J.S. (2014) Survival in Severe Sepsis and Non Fragmented Germ Cells. Virulent Infections in Children and Aborted Blood, Contraceptive Menstrual Blood Environmental Pollution. Global Journal of Medical Research: F Diseases, 14, 1-9.

[3] Samuel, E.J. (2012) Increased Prevalence of Neuroleptic Malignant Syndrome, Dementia and Fragmented Germ Cells with Reduced Endogenous Estrogen. International Journal of Science and Research (IJSR), 3, 1694-1700.

[4] Suzman, R. and Haaga, J.G. (2012) World Demography of Aging Harrisons Principles of Internal Medicine. 18th Edition, Vol. 1, McGraw Hill Medical, New York, 556.

[5] Gilliland, B.G. (1987) Systemic Sclerosis, Harrisons Principles of Internal Medicine. 11th Edition, Vol. 2, McGraw Hill Book Company, New York, 1429.

[6] Mendelsohn, J. (1987) Cancer Biology; Harrisons Principles of Internal Medicine. 11th Edition, Vol. 1, McGraw Hill Book Company, New York, 422.

[7] Elizabeth, J.S. (2014) Increased Prevalence of Renal Diseases-Metabolic Syndrome and Fragmented Germ Cells with 
Reduced Endogenous Estrogen, Androgen. International Journal of Innovative Research and Studies (IJIRS), 3, 80-83.

[8] Samuel, E.J.V., Natarajan, N., George, S., Gkulirankal, K. and Eapen, G. (2014) Increased Incidence of Diabetes Mellitus, Systemic Hypertension and Germ Cells with Endogenous Estrogen. Open Journal of Preventive Medicine, 4, 481-488. http://dx.doi.org/10.4236/ojpm.2014.46056

[9] Elizabeth, J.S. (2014) Autoimmunity and Fragmented Germ Cells. IOSR Journal of Dental and Medical Sciences (IOSR-JDMS), 13, 99-105.

[10] Elizabeth, J.S. (2014) Cancer and Germ Cells. Open Journal of Preventive Medicine, 4, 606-615.

[11] Elizabeth, J.S. (2014) Increased Prevalence of Solar Keratoses, Infectious Diseases and Rising Environmental Estrogen Equating with Aborted Blood Pollution with Consequent Ozone Depletion. IOSR Journal of Environmental Science, toxicology and Food Technology (IOSR-JESTFT), 8, 74-80.

[12] Samuel, E.J. (2014) Increasing Prevalence of Chronic Obstructive Pulmonary Disease, Tuberculosis, Lung Cancer and Rising Environmental Estrogen. International Journal of Science and Research (IJSR), 3, 1591-1598

[13] Larry Jameson, J. and Kopp, P. (2012) Genes the Environment and Disease, Mitochondrial Disorders; Harrisons Principles of Internal Medicine. 18th Edition, Vol. 1, McGraw Hill Medical, New York, 501.

[14] Samuel, E.J. (2014) Abortion, Contraception Reversal-Medical Miracle-Autologous Germ Cells Replant-Decline in Global Degenerative, Autoimmune, Neoplastic, Infectious Diseases, Decline in Rising Environmental Estrogen, Equating with Aborted Blood Pollution and Decline in Depletion of Ozone. IOSR Journal of Dental and Medical Sciences (IOSR-JDMS), 13, 93-102.

[15] Haller, H., Ito, S., Izzo Jr., J.L., Januszewicz, A., katayama, S., Menne, J., Mimran, A., Rabelink, T.J., Ritz, E., Ruilope, L.M., Rump, L. and Viberti, G. (2011) Olmesartan for the Delay or Prevention of Microalbuminuria in Type 2 Diabetes. The New England Journal of Medicine, 364, 907-917. http://dx.doi.org/10.1056/NEJMoa1007994 
Supplementary Files: Figures in Reference 7

Endogenous estrogen, androgen surveillance

Cell cycle/metabolism

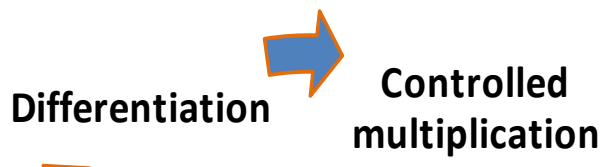

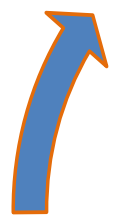

Cell growth
Degeneration apoptosis

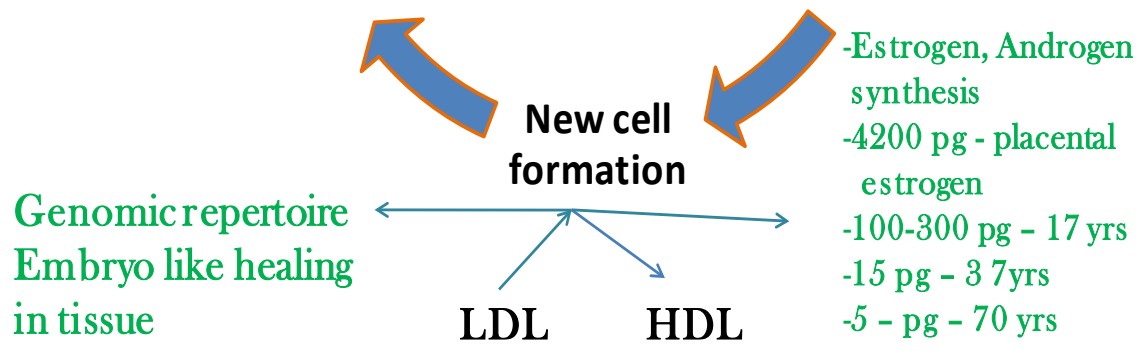

$\underline{\text { Reduced Endogenous estrogen, androgen }}$ Contraception, Abortion-Deranged Cell cycle/metabolism $\begin{array}{cc}\text { No } & \text { Un controlled } \\ \text { Differentiation } & \text { multiplication }\end{array}$ Cancer

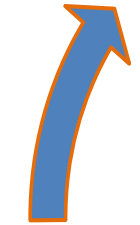

Cell growth

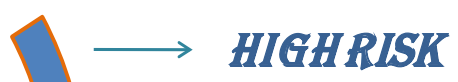
HOST

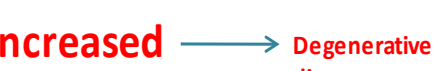

Degeneration apoptosis

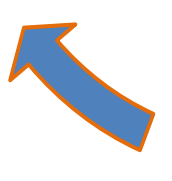

Defaulted Genomic New cell repertoire
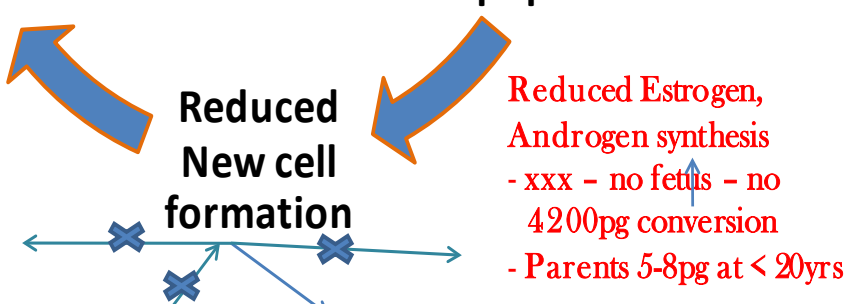

Increased LDL $\stackrel{\text { Metabolic defect }}{\text { Decreased HDL }}$ 
Supplementary Files: Figures in Reference 13

Degenerative Diseases with. Contraception at young age.

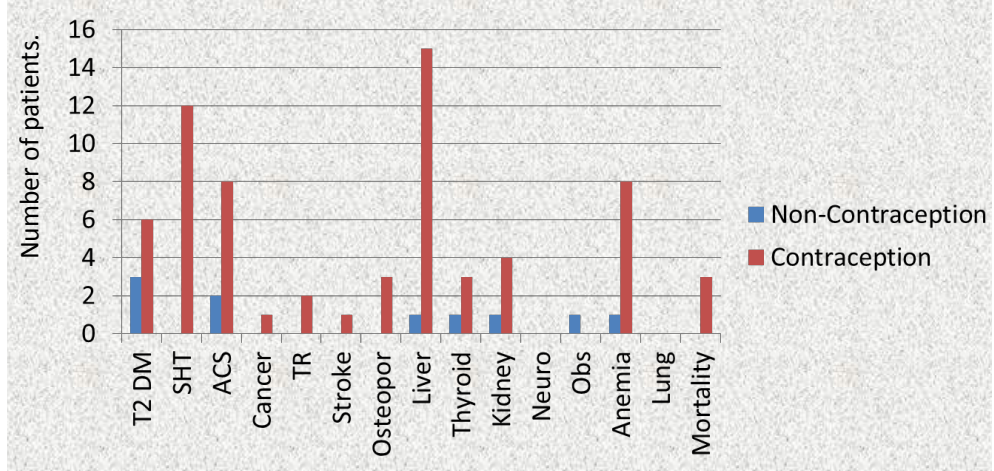

Age Group 20-35
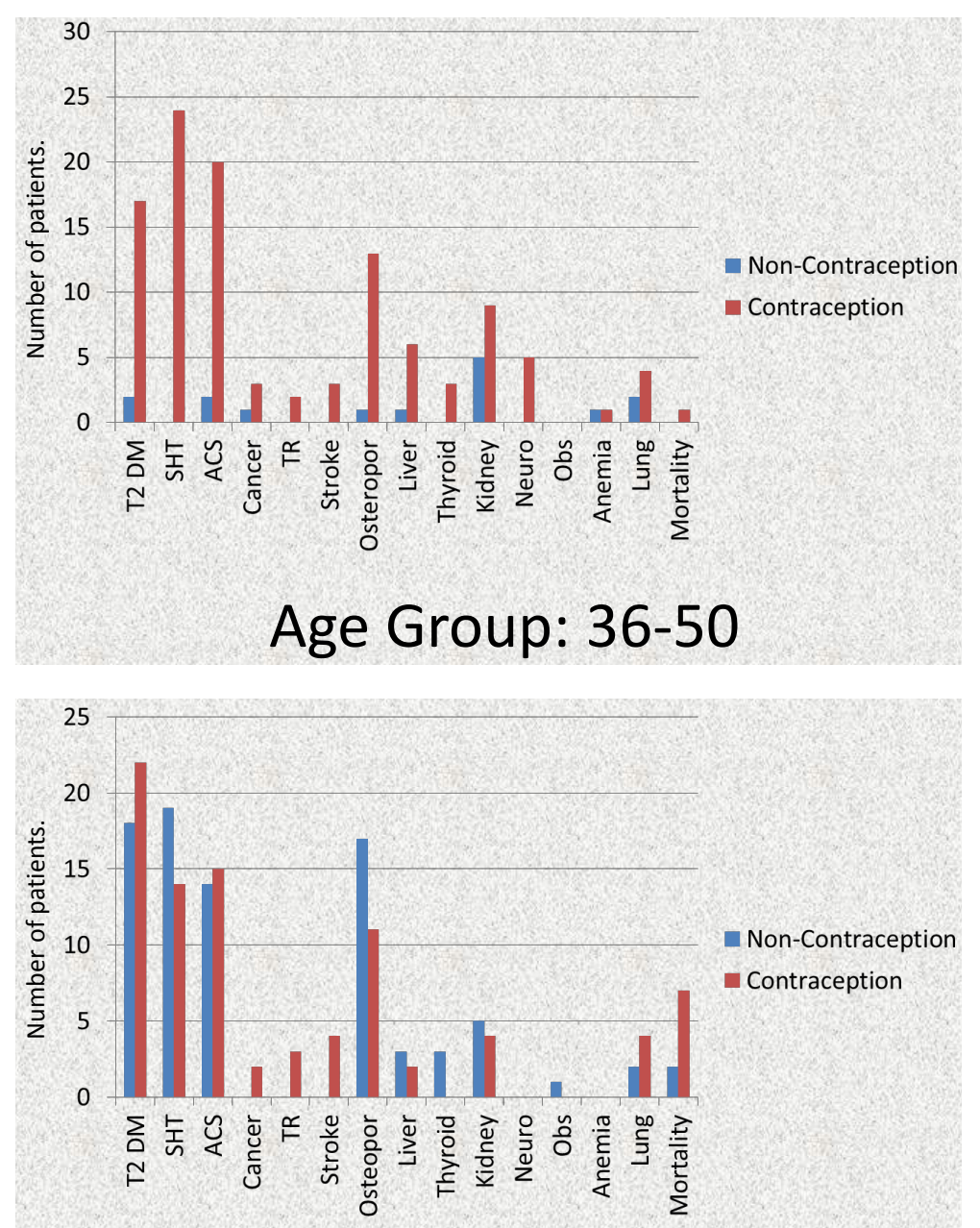

Age Group : Above 50 
- Diseases in both partners (Husband and wife)

\section{(in young age-20-50 years) InContraception only}

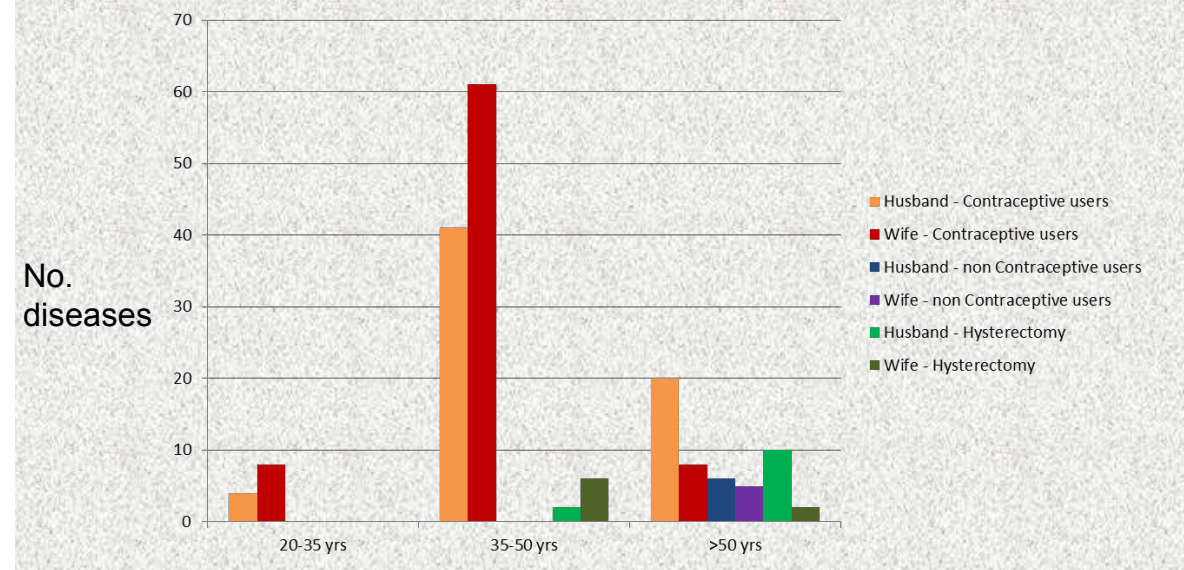

In non contraceptive users both husband and wife exhibit no disease in $20-35$ and $35-50$ age groups. Hysterectomy there was no patient in 20-35 age group

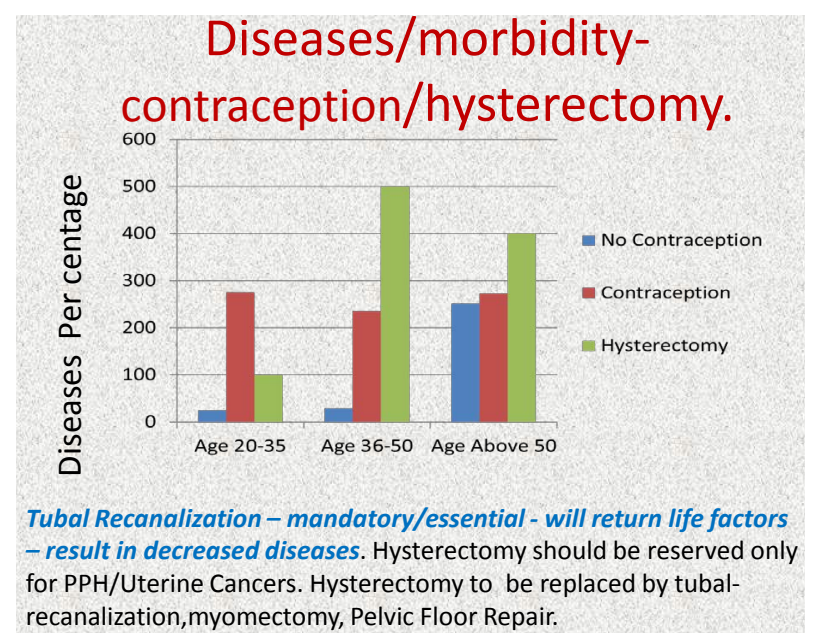

Contraception Reversal-Decline in Diseases (Medical Miracle)

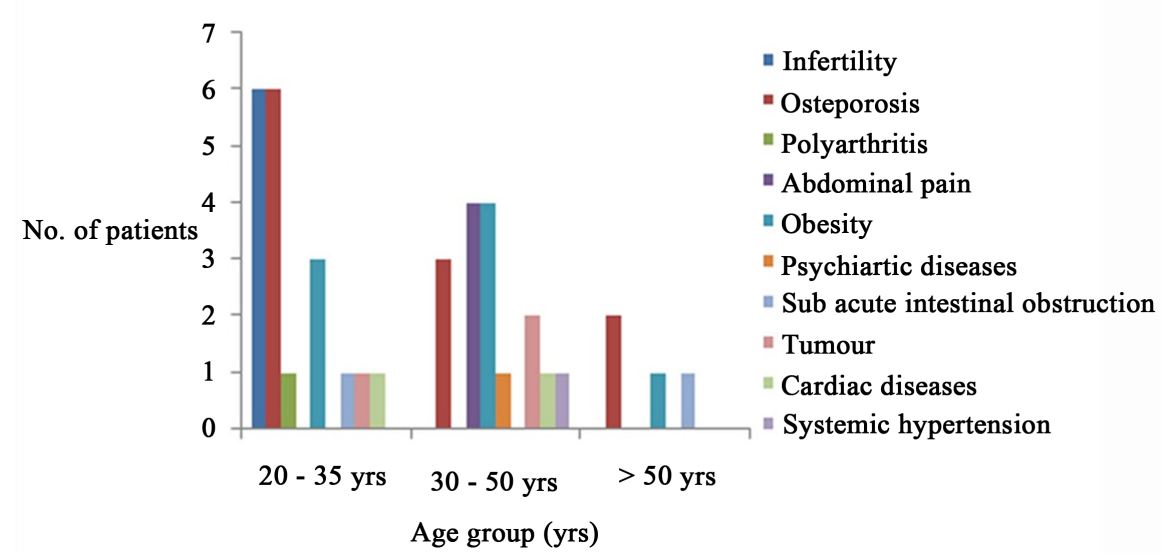

